Original Research Article

\title{
Efficacy evaluation of antidepressant drugs utilized at tertiary care centre in North Karnataka in psychiatric outpatient department
}

\author{
Harish G. Bagewadi ${ }^{1}$, Chandrashekar B. Huded ${ }^{2} *$
}

${ }^{1}$ Department of Pharmacology,

${ }^{2}$ Department of Psychiatry, Gulbarga Institute of Medical Sciences, Kalaburagi,

Karnataka, India

Received: 26 August 2019

Revised: 04 October 2019

Accepted: 05 October 2019

*Correspondence to:

Dr. Chandrashekar Huded, Email: chandruhuded@ gmail.com

Copyright: (C) the author(s), publisher and licensee Medip Academy. This is an openaccess article distributed under the terms of the Creative Commons Attribution NonCommercial License, which permits unrestricted noncommercial use, distribution, and reproduction in any medium, provided the original work is properly cited.

\begin{abstract}
Background: Depression is the major psychotic disorder affecting $9.5 \%$ of population worldwide. Present study investigates the prescribing patterns of different antidepressants evaluating their efficacy.

Methods: This was a prospective, observational study which was conducted in the out-patient department of Psychiatry and Pharmacology in Gulbarga Institute of Medical Sciences, Kalaburagi. A total of 200 cases were enrolled for the present study. Statistical analysis for efficacy was done using Wilcoxson's signed rank test.

Results: Predominantly, females suffered from depression when compared to male counterparts. In our study, monotherapy was practiced more frequently than polytherapy with 2 or more drugs. Selective serotonin reuptake inhibitors (SSRIs) like Escitalopram was found out to be the most widely used antidepressant drug.

Conclusions: Among antidepressant medications, SSRIs are preferred over others because of their better side effect profile.
\end{abstract}

Keywords: Depression, Antidepressant, Monotherapy

\section{INTRODUCTION}

Depression is a major important global public health problem due to present days lifestyle modifications, under preparedness to life situations. ${ }^{1}$ Depression can be defined as a mental state which is characterized by feelings of sadness, low self-esteem, loneliness and despair. These are also combined with psychomotor retardation or at times, social withdrawal from interpersonal contact. $^{2}$ The physical symptoms of depression which can be presented are- fatigue and reduced activity, unexplained aches, disturbed sleep or excessive sleep, changes in appetite and weight, and loss of sex drive. ${ }^{3}$ Depression accounted ascending score of for $4.46 \%$ of the total DALYs (disability adjusted life years) and $12.1 \%$ of the YLDs (years lived with disability) in 2002, when compared to $3.7 \%$ of the DALYs and $10.7 \%$ of the YLDs in $1990 .{ }^{4} \mathrm{~A}$ drug utilization study is planned to evaluate the prescribing, dispensing, administration of antidepressant medications. They also give an idea of near approximation of the disease prevalence to plan drug production and procurement. Many studies have pointed to significant changes in the prescribing habits of antidepressants. ${ }^{5}$ Thus, it is important to know the current prescribing habits of antidepressant medications. 
There are few studies in the literature which highlights on the prescribing patterns of different antidepressant medications and evaluating their efficacy. Thus, it is important to know the current trend of drug usage and the effectiveness of the drugs which are used for depression. Present study investigates the prescribing patterns of different antidepressants and evaluating their efficacy by Hamilton rating scale for depression (HRSD).

\section{METHODS}

The present study is a prospective, observational and cross sectional clinical study. Subjects were selected from patients who presented to the O.P.D. of Department of Psychiatry of Gulbarga Institute of Medical Sciences, Kalaburagi. The study was done over a period of 6 months from September-2018 to February 2019. The 200 numbers of subjects were included in the study. A prescribed proforma was prepared by the study team to collect and record the data. Institutional ethics committee permission was taken prior to the study. Informed consent was taken prior to patient's inclusion into the study.

\section{Inclusion criteria}

Inclusion criteria were outdoor patients suffering from depressive disorder attending O.P.D. of Department of Psychiatry; patients from all age groups and both the sexes are included; pregnant ladies suffering depressive disorders; understood the purpose of study and were ready to provide information regarding their health status and signed an informed consent document.

\section{Exclusion criteria}

Exclusion criteria were patients suffering from malignancies and terminally ill patients; were judged clinically to be at suicidal risk (too serious to be included in the study); had a history of allergic or serious adverse reactions to study the medications; had history of substance abuse. The following data were collected on the prescribed proforma to study the incidence, prevalence and risk factors associated with depression in our study population. All the above data of 200 patients were tabulated and put into Chi-Square test to study level of significance in the causation of depression. Antidepressant medication history is received by the subjects i.e. drug doses and frequency of the drugs, type of disease, strength of antidepressant, the duration of the treatment, etc. in the prescribed proforma. The Antidepressants were divided into three groups: Group 1 (TCAs), Group 2 (SSRIs) \& Group 3 (SNRIs). Thereby, the pattern of anti-depressant drugs used in different subsets of population was analyzed. Those subjects on TCAs or on SSRIs or on newer antidepressants (SNRIs) were subjected to detailed neuro-psychiatric examination at the point of entry into the study and were subsequently followed up at three and six months to assess the efficacy of each drug. Efficacy was assessed under the domain of psychopathology and was quantitatively evaluated by using the HDRS scale (17 items, 0-4 severity scale). The analysis of HDRS score was done statistically at baseline and at the end of 3 months and 6 months.

The HRSD, also known as the Hamilton depression rating scale (HDRS) or abbreviated to HAM-D, constitutes the multiple choice questionnaire that physicians may use to rate the severity of a patient's major depression. ${ }^{7,8}$ Each question has 3-5 possible response items which increase in severity. A score of 0-7 is considered to be normal, scores of 20 or more points towards severe depression and are usually required for entry into a clinical trial. ${ }^{9}$ Questions $18-21$ may be recorded to give further information about the depression (such as whether diurnal variation or paranoid symptoms are present), but are not part of the scale. ${ }^{10}$ Although Hamilton's original scale had 17 questions, others later developed HRSD scales with different numbers of questions, the greatest of which is 29 (HRSD-29). ${ }^{11-14}$

\section{Statistical analysis}

For the analysis of demographic profile data Chi square test and for efficacy evaluation Wilcoxson's signed rank test were used, with a $\mathrm{p}$ value of less than 0.05 , with statistically significant.

\section{RESULTS}

In our study, it was observed in (Table 1) that majority of study participants were middle aged adults within the age group of 36-50 years (73\%) followed by age group 51-64 years $(53 \%)$. Prevalence of depression is more in females (112) i.e. $56 \%$ than males (88) i.e. $44 \%$. In our study, it was evident that the average age of onset of depression was 49.2 years (Table 1) and the average length of duration of illness was 2.6 years.

Table 1: Age of onset of depression in study population.

\begin{tabular}{|c|c|c|c|c|c|c|c|}
\hline \multirow{2}{*}{$\begin{array}{l}\text { Sex of } \\
\text { patient }\end{array}$} & \multirow{2}{*}{ Items } & \multicolumn{5}{|c|}{ Age (in years) } & \multirow{2}{*}{ Total } \\
\hline & & 0-17 & 18- 35 & $36-50$ & $51-64$ & $65+$ & \\
\hline \multirow{3}{*}{ Male } & Count & 14 & 16 & 27 & 21 & 10 & 88 \\
\hline & $\%$ within sex of patient & 7 & 8 & 13 & 10 & 5 & 100 \\
\hline & $\%$ within age of onset & 58.33 & 45.6 & 39.43 & 42.85 & 25 & 42.5 \\
\hline \multirow{3}{*}{ Female } & Count & 08 & 20 & 46 & 32 & 06 & 112 \\
\hline & $\%$ within sex of patient & 4 & 10 & 23 & 16 & 03 & 100 \\
\hline & $\%$ within age of onset & 41.66 & 54.83 & 60.56 & 57.14 & 75 & 57.5 \\
\hline
\end{tabular}




\begin{tabular}{|c|c|c|c|c|c|c|c|}
\hline \multirow{2}{*}{$\begin{array}{l}\text { Sex of } \\
\text { patient }\end{array}$} & \multirow{2}{*}{ Items } & \multicolumn{5}{|c|}{ Age (in years) } & \multirow{2}{*}{ Total } \\
\hline & & 0-17 & 18- 35 & $36-50$ & 51-64 & $65+$ & \\
\hline \multirow{3}{*}{ Total } & Count & 22 & 36 & 73 & 53 & 16 & 200 \\
\hline & $\%$ within sex of patient & 11 & 18 & 36 & 26 & 08 & 100 \\
\hline & $\%$ within age of onset & 100 & 100 & 100 & 100 & 100 & 100 \\
\hline
\end{tabular}

$x^{2}=2.093 ; \mathrm{df}=4 ; \mathrm{p}=0.724$

Table 2: Utilization of different groups of antidepressant drugs.

\begin{tabular}{|lll|}
\hline Group of drug & Frequency & $\begin{array}{l}\text { Cumulative } \\
\text { percent }\end{array}$ \\
\hline SSRI & 101 & 50.5 \\
\hline TCA & 23 & 11.5 \\
\hline SNRI & 32 & 16 \\
\hline SSRI + SNRI & 27 & 13.5 \\
\hline SSRI + TCA & 17 & 8.5 \\
\hline Total & 200 & 100 \\
\hline
\end{tabular}

Table 3: Prescribing pattern of individual and combination antidepressant drugs.

\begin{tabular}{|lll|}
\hline Specific drug & Frequency & $\begin{array}{l}\text { Cumulative } \\
\text { percent }\end{array}$ \\
\hline Fluoxetine & 27 & 13.5 \\
\hline Sertraline & 22 & 11 \\
\hline Escitalopram & 40 & 20 \\
\hline Paroxetine & 4 & 2 \\
\hline Amitriptyline & 13 & 6.5 \\
\hline Venlafaxine & 11 & 5.5 \\
\hline Duloxetine & 18 & 09 \\
\hline Bupropion & 12 & 6 \\
\hline Fluoxetine+Bupropion & 11 & 5.5 \\
\hline Escitalopram+Bupropion & 16 & 8 \\
\hline Sertraline+Bupropion & 11 & 5.5 \\
\hline Sertraline+Amitriptyline & 5 & 2.5 \\
\hline Fluoxetine+Amitriptyline & 12 & 6 \\
\hline Escitalopram+Bupropion & 6 & 3 \\
\hline Total & 200 & 100 \\
\hline
\end{tabular}

In our study, it was observed in (Table 2), among 200 prescriptions, 101 prescriptions $(50.5 \%)$ contained SSRIs while $23(11.5 \%)$ contained TCAs and $32(16 \%)$ contained newer antidepressants (SNRI). SSRI plus TCA were used in $17(8.5 \%)$ patients. SSRI plus SNRI were used in $27(13.5 \%)$ patients.

In our study, it was observed in (Table 3) that among 156 cases received monotherapy, $40 \quad(20 \%)$ received escitalopram, $27(13.5 \%)$ subjects received fluoxetine, 22 $(11 \%)$ subjects got sertraline whereas $4(2 \%)$ received paroxetine. $13(6.5 \%)$ got amitriptyline, 11 (5.5\%) received venlafaxine whereas $18 \quad(9 \%)$ received duloxetine. Similarly out of 24 cases received polytherapy with 2 drugs, $16(8 \%)$ subjects were on escitalopram and bupropion, $11(5.5 \%)$ subjects were fluoxetine and bupropion, $12(6 \%)$ subjects were on fluoxetine and amitriptyline in (Table 3 ).

In our study, it was observed in (Table-4) that SSRI treated group showed baseline score of 29.5 after $1^{\text {st }}$ visit. After 3 months in the second visit HDRS score decreased to 15.4 , indicating the $41.40 \%$ of improvement. In the $3^{\text {rd }}$ visit, after 6 months there was marked $51.6 \%$ improvement with SSRIs treated group. In the TCA treated group, showed baseline score of 28.5 after $1^{\text {st }}$ visit. In the $3^{\text {rd }}$ visit, after 6 months there was marked $50.01 \%$ improvement with SNRIs treated group. In the newer SNRI treated group, showed baseline score of 28.8 after $1^{\text {st }}$ visit. After 3 months in the second visit HDRS score decreased to 15.7 , indicating the $40.05 \%$ of improvement. In the $3^{\text {rd }}$ visit, after 6 months there was marked $53.7 \%$ improvement with SNRIs treated group.

Table 4: Changes in the mean HDRS score from baseline to endpoint in patients with depression treated and followed up minimum for 6 months.

\begin{tabular}{|lllll|l|}
\hline Group of antidepressants & $\begin{array}{l}\text { At } \mathbf{1}^{\text {st }} \text { visit } \\
\text { (baseline) }\end{array}$ & $\begin{array}{l}\text { At } \mathbf{2}^{\text {nd }} \text { visit } \\
\left(\mathbf{3}_{\text {months }}\right.\end{array}$ & $\begin{array}{l}\text { \% of } \\
\text { Improvement }\end{array}$ & $\begin{array}{l}\text { At } \mathbf{3}^{\text {rd }} \text { visit } \\
\text { (6 months) }\end{array}$ & $\begin{array}{c}\text { \% of } \\
\text { improvement }\end{array}$ \\
\hline SSRI group $(\mathbf{n = 1 0 2 )}$ & 29.5 & 15.4 & 41.40 & 12.39 & 51.6 \\
\hline TCA group $(\mathbf{n = 3 3 )}$ & 28.5 & 16.2 & 37.7 & 12.77 & 50.01 \\
\hline Newer drug group (SNRI) $(\mathbf{n = 5 7 )}$ & 28.8 & 15.7 & 40.5 & 12.41 & 53.7 \\
\hline
\end{tabular}

\section{DISCUSSION}

Antidepressants were prescribed more in females than in males. Prevalence of depression is more in females (112) i.e. $56 \%$ than males (88) i.e. $44 \%$. This was consistent with the findings of other studies. ${ }^{15,16}$ The age distribution shows that the majority of patients who received the antidepressants belonged to the 21-40 years age group, in contrast to the results of a study on antidepressant use in East Asia, wherein the mean age of the patients who received antidepressant prescriptions was more than 40 years. Our study finding of $73 \%$ of the patients are over 40 years, is also the same with previous studies conducted by Uchida et al. ${ }^{17}$ 
In another study in Europe, where antidepressants were the second most commonly prescribed psychotropic drugs, a majority of the users were between 35 and 49 years, with a mean age which was greater than 40 years. ${ }^{15}$ In our study, it was observed in that monotherapy with different group of antidepressant medication was practiced in 156 patients i.e. $78 \%$ of the study population. In only 54 patients i.e. $28 \%$, polytherapy with 2 drugs of different group antidepressant medication was prescribed. Polytherapy includes combination of SSRI, TCA and newer group of antidepressants. ${ }^{18}$ Our study findings are similar with previous studies done by Chaturvedi et al. ${ }^{18}$

Majority of patients were prescribed antidepressant drugs from 3 different categories or different compounds from same category. Other studies too consistently found polypharmacy like our study where polypharmacy is about $28 \% .^{19}$ It is difficult to treat cases like treatment resistant schizophrenia or depression, mixed diagnosis and double diagnosis, drug combination is needed. But there is a lack of evidence based strategies to guide this practice. $^{20}$ In our study $61.5 \%$ of the prescriptions were having polypharmacy and is in line with that of conducted by Cuevas and Mortimer who found that incidence of polypharmacy was $41.9 \%$ and $100 \%$ respectively. ${ }^{20,21}$ It is observed in ours study that, the most frequently prescribed antidepressant was escitalopram (13.5\%) and the most frequently prescribed newer antidepressant was duloxetine (9\%). The most frequently prescribed combination therapy was that of Fluoxetine plus Amitriptyline (06\%) in the study population. The most commonly prescribed antidepressant drug in our study was escitalopram (16.5\%) followed by fluoxetine as monotherapy (15\%) both belonging to the group ssri as monotherapy. These study findings are in associations with previous studies done by Lahon et al. ${ }^{22}$

Hamilton depression rating scale (HDRS score) was used to evaluate the efficacy assessment of antidepressants. Out of all the patients treated, 102 were on SSRI, 33 patients were on TCA \& 57 were on newer combinations (SNRI). Among patients on SSRIs, there were significantly lower HDRS scores both at the end of 3 months and $6^{\text {th }}$ month compared to initials HDRS score. When HDRS scores of $2^{\text {nd }}$ and $3^{\text {rd }}$ visit of same group (SSRI) were compared, it was found that 59 cases had lower HDRS scores on third visit than second, while the rest 13 cases had equal HDRS scores on both second and third visits (Table 4). Based on our observations, it is evident that, SSRI groups of antidepressants show maximal beneficial effect after third month.

All the 33 patients on TCAs had reduced HDRS scores at end of $3^{\text {rd }}$ month and $6^{\text {th }}$ month. However, when HDRS scores of $2^{\text {nd }}$ and $3^{\text {rd }}$ visits were compared, it was found that 19 cases had less HDRS scores on $3^{\text {rd }}$ visit than $2^{\text {nd }}$ compared to baseline score, and in rest 14 cases, there were equal HDRS scores. Based on our observations, it is evident that in contrast to SSRI group, patients on TCA's have maximal benefit early i.e. (end of $3^{\text {rd }}$ month). In the newer antidepressant group containing 57 patients on SNRIs, all 57 of them had reduced HDRS scores on second visit (3 months). While 55 had reduced HDRS scores on the third visit (6 months) on comparison to second visit (3 months), only 2 cases had equal HDRS scores on both the visits. At the end of $3^{\text {rd }}$ month, It was observed that the percentage of improvement in TCA'S is almost equal with the other two groups of drugs prescribed; i.e. SSRIs and newer antidepressants and the percentage of improvement of all the group of drugs at 6 months was comparable i.e. SSRIs $-51.6 \%$, TCAs $50.1 \%$, and newer antidepressants $-53.7 \%$ respectively. This shows that there is a little difference among the three treatment groups in percentage of improvement of symptoms after three months of treatment. However, after 6 months, the percentage of improvement was 52\% for SSRI, $51 \%$ for TCA and 53\% for newer groups. Our study findings are in accordance with previous study done by Mishra et al and Deshmukh et al. ${ }^{23,24}$ Our study limitations were- our results should however be seen in the light of our small sample size, as compared to the studies with which they have been compared. The limitations of this study were the lack of patient care indicators and some of the facility indicators like the availability of drugs and the impact of cost on the drug treatment, which can increase the utility of the study. Still, many studies are required to assess the efficacy evaluation of antidepressant drugs to benefit the patients.

\section{CONCLUSION}

Females suffer from depression more when compared to their male counterparts. Monotherapy is practiced more frequently than polytherapy and conventional drugs like SSRIs are more preferred than newer antidepressants in our institution.

Funding: No funding sources

Conflict of interest: None declared

Ethical approval: The study was approved by the Institutional Ethics Committee

\section{REFERENCES}

1. Jayanthi CR, Divyashree M, Sushma M. Adverse drug reactions in psychiatry outpatients: Clinical spectrum, causality and avoidability. J Chem Pharm Res. 2013;5(8):128-35.

2. Ray S, Chogtu B. Prescribing trends in depression: a drug utilization study done at a tertiary healthcare centre. J Clin Diagn Res. 2011;5(3):573-7.

3. Reddy MS. Depression: the disorder and the burden. Indian J Psychol Med. 2010;32:1-2.

4. Pincus HA, Tanielian TL, Marcus SC, Olfson M, Zarin DA, Thompson J, et al. Prescribing trends in psychotropic medications: primary care, psychiatry, and other medical specialities. JAMA. 1998;279:52631 . 
5. Olfson M, Marcus SC, Druss B, Elinson L, Tanielian T, Pincus HA, et al. National trends in the outpatient treatment of depression. JAMA. 2002;287:203-9.

6. Ray S, Chogtu B. Prescribing Trends in Depression A drug utilization study done at a tertiary healthcare centre. JCDR. 2011;5:573-7.

7. Sengupta G, Bhowmick S, Hazra A, Datta A, Rahaman M. Adverse drug reaction monitoring in psychiatry out-patient department of an Indian teaching hospital. Indian J Pharmacol. 2011;43:1:369.

8. Hedlund JL, Viewig BW. The Hamilton rating scale for depression: a comprehensive review. J Operational Psychiatr. 1979;10:149-65.

9. Hamilton M. Development of a rating scale for Primary Depressive Illness. Br Soc Clin Psychol. 1967;6(4):278-96.

10. Williams JBW. A structured interview guide for the Hamilton Depression Rating Scale. Arch General Psychiatr. 1989;45:742-7.

11. Demyttenaere K, De Fruyt J. Getting what you ask for: on the selectivity of depression rating scales. Psychother Psychosom. 2003;72:61-70.

12. Williams JB. Standardizing the Hamilton Depression Rating Scale: past, present, and future. Eur Arch Psychiatry Clin Neurosci. 2001;251(suppl 2):II6II12.

13. Hedlund JL, Vieweg BW. The Hamilton Rating Scale for Depression: a comprehensive review. J Operational Psychiatr. 1979;10:149-65.

14. Bech P. Rating scales for affective disorders: their validity and consistency. Acta Psychiatr Scand Suppl. 1981;295:1-101.

15. Morabia A, Fabre J, Dunand JP. The influence of patient and physician gender on the prescription of psychotropic drugs. J Clin Epidemiol. 1992;45:111-6.

16. The ESEMeD/MHEDEA 2000 investigators. Psychotropic drug utilization in Europe: results from the European Study of the Epidemiology of Mental Disorders (ESEMeD) project. Acta Psychiatr Scand. 2004;109:55-64.

17. Uchida N, Chong MY, Tan CH, Nagai H, Tanaka M, Lee MS, et al. International study on antidepressant prescription pattern at 20 teaching hospitals and major psychiatric institutions in East Asia:Analysis of 1898 cases from China, Japan, Korea, Singapore and Taiwan. Psychiatr Clin Neurosci. 2007;61:522-8.

18. Chaturvedi R, Sharma P. Drug utilization study of psychotropic drugs prescribed in psychiatry OPD of L. N. medical college associated J. K. hospital, Bhopal district, Madhya Pradesh. J Evol Med Dent Sci. 2016;5(51):3242-4.

19. Chong M, Tan C, Fujii S, Yang S, Ungvari G, Tianmei SI, et al. Anti-psychotic drug prescription for schizophrenia in East Asia: Rationale for change. Psychiar Clin Neurosci. 2004;58:61-7.

20. Cuevas C, Sanz EJ. Polypharmacy in psychiatric practice in Canary Islands. BMC Psychiatr, 2004;4:18.

21. Mortimer A, Shepherd C, Rymer M, Burrows A. Primary care use of antipsychotic drugs: an audit and intervention study. Ann General Psychiatr. 2005;4:18.

22. Kingshuk Lahon, Harsha M. Shetty, Amith Paramel, Gyaneswar Sharma. A Retrospective Drug Utilization Study of Antidepressants in the Psychiatric Unit of a Tertiary Care Hospital. J Clin Diagnos Res. 2011;5(5):1069-75.

23. Mishra S, Swain T, Mohanty M. Patterns of prescription \& efficacy evaluation of antidepressants in a tertiary care teaching hospital in eastern India. Asian J Pharm Clin Res. 2012;5:3:193-6.

24. Deshmukh SA, Ismail TSES. Evaluation of psychotropic drugs use pattern among out patients attending psychiatry department at government medical college and hospital, Nagpur: a cross sectional study. Int J Pharm Bio Sci. 2012;3(3):42836.

Cite this article as: Bagewadi $\mathrm{HG}$, Huded CB. Efficacy evaluation of antidepressant drugs utilized at tertiary care centre in North Karnataka in psychiatric outpatient department. Int J Basic Clin Pharmacol 2019;8:2465-9. 